\title{
Reviews
}

\section{Hybrid nanoparticles based on sulfides, oxides, and carbides*}

\author{
A. A. Rempel ${ }^{a, b}$ \\ ${ }^{a}$ Institute of Solid State Chemistry, Ural Branch of the Russian Academy of Sciences, \\ 91 ul. Pervomaiskaya, 620990 Yekaterinburg, Russian Federation. \\ E-mail: rempel@ihim.uran.ru \\ ${ }^{b}$ Ural Federal University named after the First President of Russia B. N. Yeltsin, \\ 9 ul. Mira, 620002 Yekaterinburg, Russian Federation
}

\begin{abstract}
The methods for synthesis of hybrid nanoparticles based on sulfides, oxides, and carbides of heavy and transition metals were considered. The problem of the influence of the method of synthesis of the hybrid nanoparticles on their atomic structure, morphology of the nanomaterials, and functional properties was analyzed. The areas of practical use of the hybrid nanoparticles were proposed.
\end{abstract}

Key words: nanoparticles, sulfides, oxides, carbides.

Special attention is given nowadays to the synthesis and application of nanostructured materials (nanomaterials) based on chemical compounds. ${ }^{\mathbf{1}-3}$ This is due to the changed properties of nanomaterials compared to those of materials with the same chemical composition but with magnified scale of structural elements. ${ }^{\mathbf{4}-20}$ The changes in the properties and the appearance of unusual combinations of properties of the nanomaterials are related to the fact that the physical properties of chemical compounds are formed at distances from several nanometers to several tens of nanometers because of the characteristic nanosized radius of quasi-particles (excitons, phonons, magnons, and polarons). Therefore, a nanoparticle should have optical, electrical, magnetic, mechanical, and other prop-

* Dedicated to the Academician of the Russian Academy of Sciences I. P. Beletskaya on the occasion of her anniversary. erties differed from the properties of particles with the size $\geq 100 \mathrm{~nm}$.

Indeed, this behavior is observed, for example, for semiconductors with weakly bound excitons. The Bohr radius of exciton in these semiconductors considerably exceeds the atomic size and is equal to several nanometers. As a result, due to a decrease in the particle size of the semiconductor to several nanometers, a confinement of excitons can be achieved and quantum dots (QDs) can be obtained. The semiconducting properties of QDs differ from those for large nanoparticles and materials. At ambient temperature, it is difficult to observe lines related to exciton states in the luminescence spectra of bulky semiconductors. The quantum yield from these states is low because of high values of effective radii of exciton. In addition, at ambient temperature excitons actively decompose because of thermal motion. The energy of an exciton

Published in Russian in Izvestiya Akademii Nauk. Seriya Khimicheskaya, No. 4, pp. 0857-0869, April, 2013. 
increases if the motion is restricted in at least one dimension to linear sizes compared to its Bohr radius. Due to this, it is possible to develop new materials and instruments, whose operation is based on the physical processes determined by exciton states. In QDs, the motion of an exciton is restricted in all three dimensions. When a zerodimension semiconductor is placed in a dielectric matrix, an additional enhancement of the Coulomb interaction between the electron and hole can be attained. A substantial increase in the quantum yield (up to $80 \%$ ) can be achieved when QDs are surrounded by a shell of a semiconductor with a broadened forbidden band (for example, hybrid QDs with the core-shell structure CdSe/ZnS). ${ }^{10}$

Therefore, studies in the area of synthesis of hybrid nanoparticles, i.e., nanoparticles consisting of at least two phases (organic or inorganic) gained the more important role in the recent time. Hybrid nanoparticles can have the core-shell structure, the centaur structure, or a more complicated structure. Hybrid nanoparticles can be incorporated into the structure of composite materials. The necessity of hybrid nanoparticles is related, on the one hand, to solving of the problem of nanoparticle stability in time and, on the other hand, to the formation of beforehand specified functional properties of the nanomaterials, i.e., to practical demands.

In this review, we consider the results of studies on the synthesis, structure, properties, and use of hybrid nanoparticles based on sulfides $(\mathrm{CdS}, \mathrm{PbS})$, oxides $\left(\mathrm{TiO}, \mathrm{TiO}_{2}\right.$, $\mathrm{VO}, \mathrm{NbO}$ ), and carbides (WC, $\mathrm{VC}$ ), which were carried out at the Laboratory of Non-Stoichiometric Compounds at the Institute of Solid State Chemistry (Ural Branch, Russian Academy of Sciences (RAS)) in a tight cooperation with many research groups in Russia (N. D. Zelinsky Institute of Organic Chemistry (RAS), Institute of Organic Synthesis (Ural Branch, RAS), Institute of Metal Physics (Ural Branch, RAS), G. K. Boreskov Institute of Catalysis (Siberian Branch, RAS), and Institute of Chemistry (Far Eastern Branch, RAS)) and abroad (ErlangenNuremberg University, Regensburg University, Stuttgart University, Graz Technical University, SCK-CEN, and Tokyo Gakugei University).

\section{Sulfide nanoparticles with organic shell}

Chemical methods for the preparation of QDs based on nanoparticles of heavy metal chalcogenides are presently developed vigorously. ${ }^{21-29}$ The fluorescence properties of chalcogenide QDs can be used in future as biomarkers, whose role are presently played by organic dyes. ${ }^{25-28}$ Advantages obtained in this case are high brightness and life-time of luminescence under the action of exciting UV irradiation (photostability), as well as diversity of colors achieved by the synthesis of QDs of different sizes. ${ }^{\mathbf{2 6}-\mathbf{3 3}}$ The dispersion medium of solutions of QDs obtained by the popular to date synthesis methods represents toxic organic compounds, which substantially complicates their bioapplication. ${ }^{27}$ Therefore, the problem of the development of a method for QD synthesis in an aqueous dispersion medium, which is biologically compatible with an internal medium of a living cell, was stated at the Laboratory of Non-Stoichiometric Compounds as early as 2002. Due to fluorescence of biocompatible QDs, the migration of individual macromolecules in the living biological cell can be monitored, the cell structure can be visualized, and various diseases can be diagnosticated using standard fluorescence microscopy. ${ }^{26-28}$

A stable aqueous colloidal solution of cadmium sulfide nanoparticles was obtained ${ }^{34}$ by the method of chemical condensation as a result of the work on solving this problem. In this method, aqueous solutions of cadmium chloride and sodium sulfide are used as sources of cadmium and sulfur atoms, respectively, and an aqueous solution of ethylenediaminetetraacetic acid (EDTA) disodium salt is used as a stabilizer to prevent the coagulation of colloidal particles. ${ }^{34,35}$ Immediately after preparation, the solution under daylight is colored in bright lemon-yellow. At room temperature, the solution remains stable within 1 month, whereas at lowered temperature (in a standard refrigerator at $4{ }^{\circ} \mathrm{C}$ ) it remains stable within 1 year. A true aqueous solution of sodium chloride $\mathrm{NaCl}$ and disubstituted EDTA sodium salt is the dispersion medium of the solution. The structure and properties of the dispersion phase were studied by X-ray diffraction, optical fluorescence, and electron microscopic analyses.

The nanoparticle sizes were measured directly in solution by dynamic light scattering on a Zetasizer Nano-ZS analyzer of dispersions ${ }^{36}$ After drying of the solution, the nanoparticle size was studied by semicontact atomic force microscope (sc-AFM) using an NTEGRA Spectra probe nanolaboratory ${ }^{36}$ Immediately after a microdrop of a colloidal solution was deposited on the support, centrifuging on a Sawates SM 180-Hp250HDMS instrument with a velocity of $3000 \mathrm{rpm}$ was carried to separate the fraction of large particles. The image of the surface relief obtained by the sc-AFM method is shown in Fig. 1. It is seen that the atomically smooth mica surface mainly contain fine round nanoparticles, among which some comparatively large particles can be observed. The measurements of the relief of the sample surface by sc-AFM revealed two types of objects: nanoparticles with the size $<10 \mathrm{~nm}$ and the density $\sim 100$ particles per $1 \mu \mathrm{m}^{2}$ and large particles with a size of $30-45 \mathrm{~nm}$ and a density of $\sim$ particle per $1 \mu \mathrm{m}^{2}$. The nanoparticle size was determined by the height of the surface relief. The mean size of the particles was $2.9 \mathrm{~nm}$. The histogram of the nanoparticle size distribution was approximated by a function of normal distribution with the maximum of the distribution function at $2.6 \mathrm{~nm}$.

The nanoparticle size was measured by dynamic light scattering directly in an aqueous suspension. The suspension of particles was placed in a $3-\mathrm{cm}^{3}$ cell and irradiated 


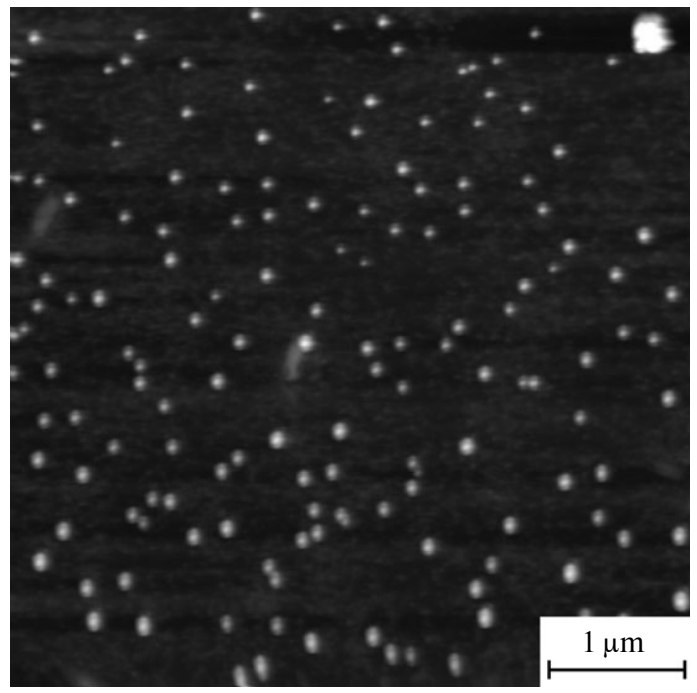

Fig. 1. Quantum dots of CdS on the mica surface after centrifuging with a velocity of $3000 \mathrm{rpm}$. The surface relief was measured by the sc-AFM method.

with a helium - neon laser at a wavelength of $633 \mathrm{~nm}$. The scattered radiation detector was arranged at an angle of $173^{\circ}$. The study of the size distribution function of scattering sites showed that the most part of the particles are $15 \mathrm{~nm}$ in size.

The sizes of the CdS QDs determined by different methods somewhat differ. This can be explained by the fact that the method of dynamic light scattering makes it possible to determine the sizes of micelles including the solvate shell, and the sizes of the micelle core can be determined by sc-AFM. The CdS nanoparticles in an aqueous solution are localized in micelles, whose composition includes molecules of the stabilizer and polarized molecules of the solvent. ${ }^{34}$ These formations consisting of the CdS nanoparticles, stabilizing layer, and solvate shell of molecules of the dispersion medium are scattering sites. The model of a micelle with the CdS QD localized inside is shown in Fig. 2.

The measurement of the $\zeta$-potential showed that the state of nanoparticles corresponds to the boundary of the stability zone and, hence, the possibility of their coagulation cannot be excluded. Therefore, rare large particles observed in all experiments can be agglomerates of nanoparticles.

The detailed studies of the structure of CdS nanoparticles performed on dry residues by transmission electron microscopy (TEM) and X-ray diffraction analysis showed that the particles with the size $<5 \mathrm{~nm}$ have a disordered close packed structure and space group P6 (see Refs 37-40) and different photoluminescence colors ranging from green to orange, depending on the age of the solution. The maximum size of coagulates determined by TEM in the dry precipitates isolated from solutions in 1, 2, and 4 months achieved $10 \mathrm{~nm}, 100 \mathrm{~nm}$, and $1 \mu \mathrm{m}$, respectively. ${ }^{34}$

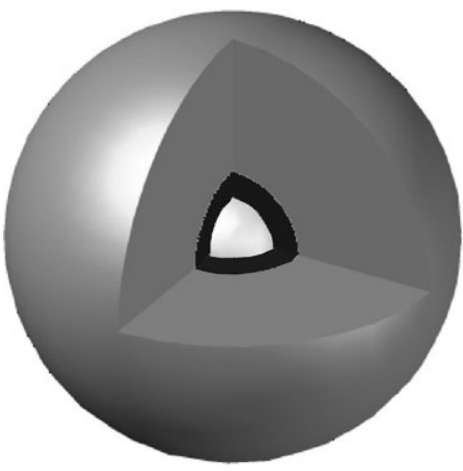

Fig. 2. Quantum dot of CdS (internal sphere) $3 \mathrm{~nm}$ in diameter encapsulated into a micelle; the stabilizing organic shell with a thickness of $\sim 1 \mathrm{~nm}$ based on EDTA molecules (dark sphere), and the aqueous solvate shell with a thickness of $5 \mathrm{~nm}$ (gray color). The sizes of the quantum dot stabilizing the shells and micelles were measured by the X-ray, thermal neutron, and light scattering methods.

The following problem was stated ${ }^{\mathbf{2 1}}$ for the detailed study of the coagulation processes in a stable solution: to study the time stability of the optical properties (fluorescence and absorbance wavelengths) of nanoparticles in aqueous solutions with different initial concentrations of cadmium and sulfur ions and the biocompatible organic stabilizer using cadmium sulfide as an example.

For this purpose, numerous solutions were obtained in a wide range, and some of them turned out to be transparent or turbid, and some solutions contained a precipitate. A solution considered to be transparent if no scattering of a laser beam with a wavelength of $650 \mathrm{~nm}$ passing through the solution was observed under natural irradiation. In the case of visible scattering of a laser beam, the solution considered turbid. Transparent solutions were yellow-green, whereas turbid solutions and precipitates were yellow.

The boundary values of the initial concentrations were determined for each of three types of solutions. The highest initial concentration for the stabilizer at which the solution remained transparent was $C\left(\mathrm{H}_{2} \mathrm{Y}^{2-}\right)=24 \mathrm{mmol} \mathrm{L}^{-1}$, and for sulfur and cadmium ions $C\left(\mathrm{Cd}^{2+}\right)=C\left(\mathrm{~S}^{2-}\right)=$ $=12.5 \mathrm{mmol} \mathrm{L}^{-1}$. The regions of concentrations for a turbid solution by the stabilizer content is restricted by the value $C\left(\mathrm{H}_{2} \mathrm{Y}^{2-}\right)=50 \mathrm{mmol} \mathrm{L}^{-1}$, while by the content of cadmium and sulfur ions it is $C\left(\mathrm{Cd}^{2+}\right)=C\left(\mathrm{~S}^{2-}\right)=30 \mathrm{mmol} \mathrm{L}^{-1}$. The region of concentrations for a solution with a precipitate is restricted by the initial concentration of the stabilizer in a solution maximum possible under normal conditions and equal to $C\left(\mathrm{H}_{2} \mathrm{Y}^{2-}\right)=70 \mathrm{mmol} \mathrm{L}^{-1}$, since the solubility limit of EDTA disodium salt is ${ }^{35} 108 \mathrm{~g} \mathrm{~L}^{-1}$, or $\sim 0.3 \mathrm{~mol} \mathrm{~L}^{-1}$.

Special experiments were carried out to establish the influence of the non-stoichiometric ratio of cadmium and sulfur ions on the stability of the solution at the initial concentrations of cadmium and EDTA disodium salt ions 
$C\left(\mathrm{Cd}^{2+}\right)=C\left(\mathrm{H}_{2} \mathrm{Y}^{2-}\right)=12.5 \mathrm{mmol} \mathrm{L}^{-1}$. It was found in these experiments that, as the initial concentration of sulfur ions increases to $C\left(\mathrm{~S}^{2-}\right)=15 \mathrm{mmol} \mathrm{L}^{-1}$, the solution gets turbid and then a precipitate is formed. If the initial concentration of sulfur ions is lower than $12.5 \mathrm{mmol} \mathrm{L}^{-1}$, the solution remains transparent.

The stability of transparent solutions is provided by preventing nanoparticle coagulation due to the formation of a shell on them consisting of complexes of EDTA disodium salt ions with cadmium ions. Turbid solutions are formed due to coagulation, which occurs because of an insufficient (relative to the cadmium and sulfur ions) concentration of the stabilizer. In turbid solutions, the size of the coagulates becomes comparable with the wavelengths of the visible optical range. ${ }^{\mathbf{4 1}}$

Transparent and turbid solutions and the precipitate had fluorescence, regardless of the initial concentrations. However, a correlation between the fluorescence wavelength and the time from the moment of synthesis of the solution was observed only for the transparent solution. The fluorescence of the turbid solution and precipitate was mainly red-orange and brown, and these colors did not change with time.

The transparent solution dried on the supports was characterized by different fluorescence wavelengths depending on the time from the moment of synthesis. The fluorescence wavelength of the transparent solution dried on the supports and also the absorbance of the solution itself changed with time (Fig. 3). It is seen from the plot that the more time passed from the moment of synthesis, the higher the absorbance of the transparent solution. The highest absorption was observed for the turbid 6-month solution. The transparent 1-weak solution and the 6-month solution that got turbid were stored at room temperature, whereas transparent 1-month and 1-year solutions were stored at $4{ }^{\circ} \mathrm{C}$. All four solutions were obtained under

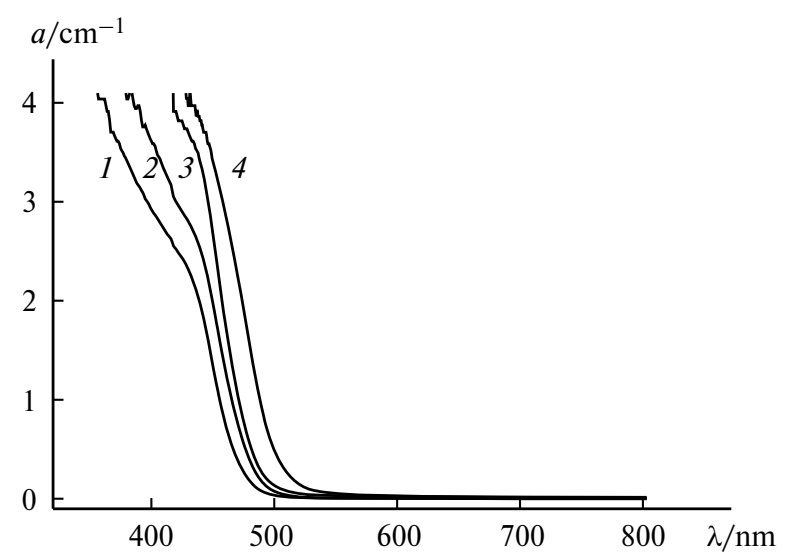

Fig. 3. Absorbance $v s$ age of a CdS solution. Spectra 1, 2, and 3 correspond to the absorbance of transparent solution of an age of 1 week, 1 month, and 1 year. The molar absorption coefficient of spectrum 4 corresponds to a 6 -month turbid solution. similar conditions, and each initial concentration was $125 \mathrm{mmol} \mathrm{L}^{-1}$.

The forbidden bands $\left(E_{\mathrm{g}}\right)$ equal to $2.69,2.66$, and $2.66 \mathrm{eV}$ were calculated using the obtained spectral data for solutions of an age of 1 week, 1 month, and 1 year, respectively. The $E_{\mathrm{g}}$ value of CdS particles of the solution, which turned turbid and for which the absorption observed was maximum, was $2.56 \mathrm{eV}$. Evidently, the greater the age of the solution, the smaller the forbidden band width. It is shown that for a CdS single crystal $E_{g}=2.36 \mathrm{eV}$, and according to some data, it can achieve $2.5 \mathrm{eV}$.

The changes detected with time in the fluorescence wavelengths and forbidden band width can be explained by the coagulation of nanoparticles in solution. The observed blue shift of fluorescence is consistent with the conclusion, $\mathbf{3 , 2 7 , 4 2 - 4 4}$ according to which the larger the nanoparticle size, the longer the fluorescence wavelength. The fact that solutions of coagulates of $\mathrm{CdS}$ nanoparticles have intense fluorescence with the wavelengths corresponding to the red color indicates the appearance of atomic defects both in the internal sphere and on the surface of the nanoparticles. The observed change in the optical properties of the $\mathrm{CdS}$ nanoparticles with time will further allow one to control the properties of QDs obtained in aqueous solutions.

Thus, it was found that the time stability of the fluorescence wavelengths corresponding to the green color of a transparent solution of CdS nanoparticles is $\leq 2 \mathrm{~h}$. After this, the color of the solution dried on the subsequent supports changed from green to red for $\sim 100 \mathrm{~h}$ under the UV radiation, and the fluorescence wavelength corresponding to the red color further remains unchanged. According to the studies of the absorption spectra, the fluorescence wavelength changes due to both a decrease in the forbidden band width and an increase in the fluorescence intensity related to atomic defects in the cadmium sulfide nanoparticles. It was shown that the forbidden band width of the CdS nanoparticles is larger than that in the case of polycrystalline cadmium sulfide, which confirms the blue shift theory for semiconducting nanoparticles with sizes smaller than the Bohr radius of exciton.

Thus, the obtained aggregate-stable solutions are stable in the sense of a constant nanoparticle size only during a restricted time, which substantially is elongated with a decrease in the temperature of the solution. The solutions can successfully be used for various purposes within the stability period. The application of stable solutions of cadmium sulfide solutions was described. ${ }^{45-47}$ The solutions were shown to be successfully used for the visualization of the structure of primary biological cells and interwoven cell clustures and for the study of viral effects on them.

The fluorescence spectra of the used solutions contained a peak, whose maximum corresponded to a wavelength of $486 \mathrm{~nm}$ upon excitation with the light with 
a wavelength of $355 \mathrm{~nm}$. To elucidate the dynamics of interaction of the nanoparticles with cells, the duration of incubation of the solutions with cell cultures was varied from $15 \mathrm{~min}$ to $72 \mathrm{~h}$. Epithelial cells of the human nasal cavity, peritoneal neurophiles of rats, interwoven cells of monkey kidney (Vero), and human embryonic lung fibroblast (HEL) cells (one- and three-day lines) were used for the preparation of conjugates. Interwoven cells were cultivated on cover glasses in an RPMJ nutrient medium containing glutamine and cattle serum $(10 \%)$ at $37{ }^{\circ} \mathrm{C}$. The concentration of the suspension was 100 thousands of cells per $1 \mathrm{~mL}$. A solution of CdS nanoparticles was added to a suspension of cells in a concentration of $10 \mu \mathrm{g} \mathrm{mL}-1$. At the first stage, intact (healthy) cells were incubated with the QDs. To look through the cells, the cover glasses were taken out of cultural vials, dried in air, and analyzed with a fluorescence microscope. In addition, the interaction of nanoparticles with the Vero line cells infected with a Herpes simplex virus (HSV). The infectious titer of the virus was $4.5 \log (\mathrm{CET} 50 / \mathrm{mL}$ ) (CET is the cytopathic effect titer; 50 is the number of cells died because of the virus effect) in $20 \mu \mathrm{L}$. The fluorescence of the prepared samples was detected on a Leica 2500M DM optical fluorescence microscope. An HB0100/W2 mercury lamp served as an excitation source. The ultraviolet filter made it possible to excite fluorescence in the wavelength range from 335 to $425 \mathrm{~nm}$.

Depending on the type of cells and duration of incubation, different stages of interaction of QDs with cells were observed. It was shown that the penetration of the nanoparticles into the cell is preceded by their accumulation on the membrane.

The image (Fig. 4) was obtained after the conjugation of the HEV cell culture with the CdS nanoparticles. Individual elongated cells are well seen. The nanoparticles incorporate into the cytoplasm and dye it. The structure,

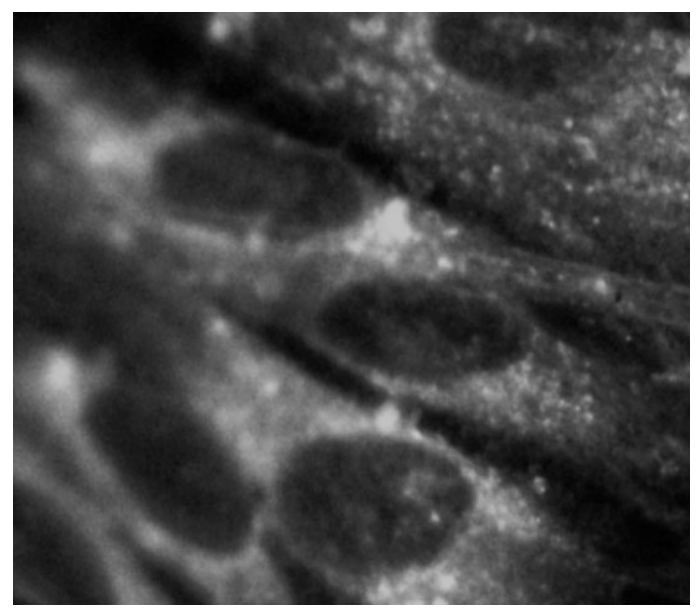

Fig. 4. Image of the HEL cells conjugated with CdS nanoparticles for $30 \mathrm{~min}$. cytoplasm, and nucleus of the cells adjacent to each other are well seen. In addition, heterogeneities characteristic of cytoplasm are observed. The cores are dark and surrounded by bright strips. It is most likely that the penetration of the nanoparticles into the nuclei is hindered, and the nanoparticles are accumulated on the nucleus membrane. An analysis of the same sample in 1 month showed that the fluorescence intensity remained almost unchanged, which suggests the time stability of the obtained samples (conjugates).

The method described allows one to monitor the functional state of the cell. The cytoplasm and nucleus of a regular shape are observed for young cells only. At the same time, in mature cells the nanoparticles are accumulated along the contour of nucleus membrane that became denser and changed the shape. In the cells infected with a virus and incubated with the CdS nanoparticles, no distinct structurization was observed but the complete destruction of the cell under the effect of viral reproduction was seen.

\section{Sulfide-oxide nanoparticles}

Hybrid nanoparticles of another important type, sulfide-oxide, were synthesized for photocatalysts operating under the visible light. The method applied for the preparation of the above described stable aqueous solution cannot be used for this synthesis, because it is necessary to provide a substantial degree of adhesion of the sulfide phase to the oxide one.

Therefore, a slow sulfidizer (sulfur donor), namely, thiourea, was used when sulfide nanoparticles was deposited on the oxide nanoparticles. ${ }^{\mathbf{4 8}-\mathbf{5 0}}$

The problem of water and air purification from various organic contaminations is especially significant presently. 1,51-53 Photocatalysis with superconductors found wide use as a purification method. In the photocatalytic method of water decontamination, oxidation on titanium dioxide $\left(\mathrm{TiO}_{2}\right)$ under UV irradiation is used in most cases. It is known that the main drawback of $\mathrm{TiO}_{2}$, from the viewpoint of practical use, is its insufficiently narrow forbidden band and, as a consequence, a low photoactivity under the action of solar light in which the content of wavelengths $<365 \mathrm{~nm}$ is only several percents. ${ }^{\mathbf{5 4 , 5 5}}$ Therefore, the absorption band of the $\mathrm{TiO}_{2}$ photocatalyst should be shifted to the long-wavelength range of the optical spectrum in order to increase the efficiency of the catalytic process. In this connection, a complicated catalyst was designed using semiconducting cadmium sulfide $(\mathrm{CdS}){ }^{\mathbf{4 8}-\mathbf{5 0}}$ The design was the chemical construction of the composite catalyst in which photogenerated electrons and holes are spatially separated to increase the rate of photocatalytic processes. ${ }^{\mathbf{5 5}}$ Due to the deposition of particles of the CdS semiconductor having a narrower forbidden band on broad-band $\mathrm{TiO}_{2}$, the photosensitivity region of the photo- 
catalyst extends from 365 to $515 \mathrm{~nm}$ and, hence, the photocatalyst can be used for the photocatalytic decomposition of water for hydrogen formation ${ }^{\mathbf{5 6}-\mathbf{5 8}}$ under solar light. Nanocrystalline $\mathrm{TiO}_{2}$ with a high specific surface area was to used for the catalytic activity of the new photocatalyst based on weight unit would be maximally high. The catalysts based on a composite of cadmium sulfide and titanium dioxide, $\mathrm{CdS} @ \mathrm{TiO}_{2}$, which are active under the visible light, were obtained by the two-stage process. The first stage was the synthesis of nanocrystalline cadmium sulfide particles by chemical precipitation from aqueous solutions, and the second stage was the deposition of CdS on the commercial powder $\mathrm{TiO}_{2}$ with the known specific surface.

Sodium sulfide and $\mathrm{Na}_{2} \mathrm{~S}$ and thiocarbonic acid diamide (thiourea) $\mathrm{N}_{2} \mathrm{H}_{4} \mathrm{CS}$ served as sulfidizers. The rates of nucleation and growth of CdS particles in solution depend strongly on the type of the sulfidizer, and for $\mathrm{Na}_{2} \mathrm{~S}$ these values are rather high and the particle size of the solid phase is very low. Therefore, aqueous solutions of $\mathrm{Na}_{2} \mathrm{~S}$ were used for the deposition of $\mathrm{CdS}$ on the nanocrystalline powder of $\mathrm{TiO}_{2}$ with a highly developed surface $\left(\mathrm{TiO}_{2}\right.$ Hombifine $\mathrm{N}$ (anatase, $\left.100 \%\right)$ ). When sulfidizer $\mathrm{Na}_{2} \mathrm{~S}$ is used, the size of the formed CdS particles does not exceed $5 \mathrm{~nm} .{ }^{59}$ The deposition of $\mathrm{CdS}$ on $\mathrm{TiO}_{2}$ with a lower specific surface $\left(\mathrm{TiO}_{2}\right.$ Degussa $\mathrm{P} 25$ (rutile, $25 \%$; anatase, $75 \%$ )) was carried out by the deposition of sulfide as a thin polycrystalline discrete film ${ }^{60,61}$ using $\mathrm{N}_{2} \mathrm{H}_{4} \mathrm{CS}$ as a sulfidizer.

The synthesis and deposition of $\mathrm{CdS}$ were carried out in a narrow concentration range from 5 to $50 \mathrm{mmol} \mathrm{L}^{-1}$ for the major reactants, cadmium chloride $\mathrm{CdCl}_{2}$, and sulfidizers $\left(\mathrm{Na}_{2} \mathrm{~S}\right.$ or $\left.\mathrm{N}_{2} \mathrm{H}_{4} \mathrm{CS}\right)$. The $\mathrm{pH}$ value of the solution was controlled by the addition of small amounts of an alkaline solution $\left(\mathrm{NaOH}, 1 \mathrm{~mol} \mathrm{~L}^{-1}\right)$ to have $\mathrm{pH} 12-12.5$. The temperature of the reaction mixture was maintained in a thermostat at $25-50^{\circ} \mathrm{C}$. When synthesizing some samples, the reaction mixture was stirred.

The overall stoichiometric equation of CdS formation from aqueous solutions of soluble cadmium salts and sulfidizer $\left(\mathrm{N}_{2} \mathrm{H}_{4} \mathrm{CS}\right.$ and $\left.\mathrm{Na}_{2} \mathrm{~S}\right)$ can be presented as two equations

$$
\begin{aligned}
& \mathrm{CdL}_{n}^{2+}+\left(\mathrm{NH}_{2}\right)_{2} \mathrm{CS}+2 \mathrm{OH}^{-}= \\
&=\mathrm{CdS}+n \mathrm{~L}+\mathrm{H}_{2} \mathrm{NCN}+\mathrm{H}_{2} \mathrm{O} \\
& \mathrm{CdL}_{n}{ }^{2+}+\mathrm{S}^{2-}=\mathrm{CdS}+n \mathrm{~L}
\end{aligned}
$$

where $\mathrm{CdL}_{n}{ }^{2+}$ is the soluble complex ion. In this project, $\mathrm{C}_{10} \mathrm{H}_{14} \mathrm{~N}_{2} \mathrm{O}_{8} \mathrm{Na}_{2}$ (EDTA), sodium thiosulfate $\mathrm{Na}_{2} \mathrm{~S}_{2} \mathrm{O}_{3}$, citric acid $\mathrm{H}_{3} \mathrm{C}_{6} \mathrm{H}_{5} \mathrm{O}_{7}$, ammonia $\mathrm{NH}_{3}$, and alkali $\mathrm{NaOH}$ were used as ligands $\mathrm{L}$ (complexing agents). The choice of complexing agents is caused by the formation constants of the corresponding complex ions, whose values should be fairly high to suppress the hydrolysis of $\mathrm{Cd}^{2+}$ ions, i.e., to prevent the formation of oxygen-containing cadmium compounds poorly soluble in water. At the same time, the concentration of free $\mathrm{Cd}^{2+}$ ions in solution should be sufficient for the achievement of the solubility product of CdS.

The second stage of the preparation of the catalyst samples based on hybrid nanoparticles $\mathrm{CdS} @ \mathrm{TiO}_{2}$ was the deposition of the CdS nanoparticles on $\mathrm{TiO}_{2}$. The $\mathrm{TiO}_{2}$ nanopowder was placed in the reaction flask at the stage of preparation of the reaction mixture for the synthesis of $\mathrm{CdS}$. The phase analysis and structural certification of the obtained CdS@ $\mathrm{TiO}_{2}$ systems performed by the diffraction method showed that the structure of cadmium sulfide nanoparticles corresponds to the disordered close packed structure with the space group P6 (see Refs 37-40). The short order of the disordered close packed structure of $\mathrm{CdS}$ is similar to that for polycrystalline modifications of $\mathrm{CdS}$ of the $B 3$ (sphalerite) and $B 4$ (wurtzite) types and is distinguished only by the absence of periodicity in the arrangement of close packed layers of cadmium and sulfur. An analysis of the X-ray diffraction patterns showed that the particle size of CdS prepared using $\mathrm{NaOH}$ as a complexing agent is $\sim 5 \mathrm{~nm}$, that when using ammonia is 3-4 $\mathrm{nm}$; and the particle size of the samples prepared with citric acid, EDTA, and sodium thiosulfate is $<2 \mathrm{~nm}$. For all types of photocatalysts, the nanoparticle size of titanium dioxide is $5 \mathrm{~nm}$.

To confirm the data on the two-phase character of the CdS@ $\mathrm{TiO}_{2}$ samples obtained by the deposition of cadmium sulfide on titanium dioxide, the TEM studies were performed. ${ }^{50}$ The images of the CdS@ $@ \mathrm{TiO}_{2}$ (Degussa P25) and CdS@ $\mathrm{TiO}_{2}$ (Hombifine) samples obtained from aqueous solutions at $25^{\circ} \mathrm{C}$ are shown in Fig 5. It follows from the detailed analysis of the images that the cadmium sulfide nanoparticles isolated from each other tightly adjoin larger titanium dioxide nanoparticles thus forming hybrid nanoparticles.

The activity of the $\mathrm{CdS} @ \mathrm{TiO}_{2}$ catalysts was studied in the oxidation of ethanol to acetaldehyde in a flow system. To oxidize ethanol, the catalyst was deposited on the glass support. Oxidation occurred under the light from a $\mathrm{ZhS}$ 11 mercury lamp (transmission at the wavelength $>400 \mathrm{~nm}$ ) in a sealed reactor. Under these conditions, the catalytic activity of pure, i.e., unmodified with $\mathrm{CdS}$, titanium oxide $\mathrm{TiO}_{2}$ is negligible.

The rate values were estimated from the determination of the increase in the acetaldehyde content in the reaction mixture on a gas chromatograph. The catalytic activity of the CdS@TiO 2 (Degussa 25) system turned out to be close to that for the CdS@ $\mathrm{TiO}_{2}$ (Hombifine N) system, being 0.34 ( $\mu \mathrm{mol}$ of acetaldehyde) $\mathrm{h}^{-1}$. The activity of $\mathrm{CdS} @ \mathrm{TiO}_{2}$ (Hombifine N) without the addition of any complexing agent is 0.1 ( $\mu$ mol of acetaldehyde) $\mathrm{h}^{-1}$, which is substantially lower than the activity of all systems in which complexing agents were used. It was established that the highest activity belongs to the samples obtained from solutions of the amine and citrate complex salts of 

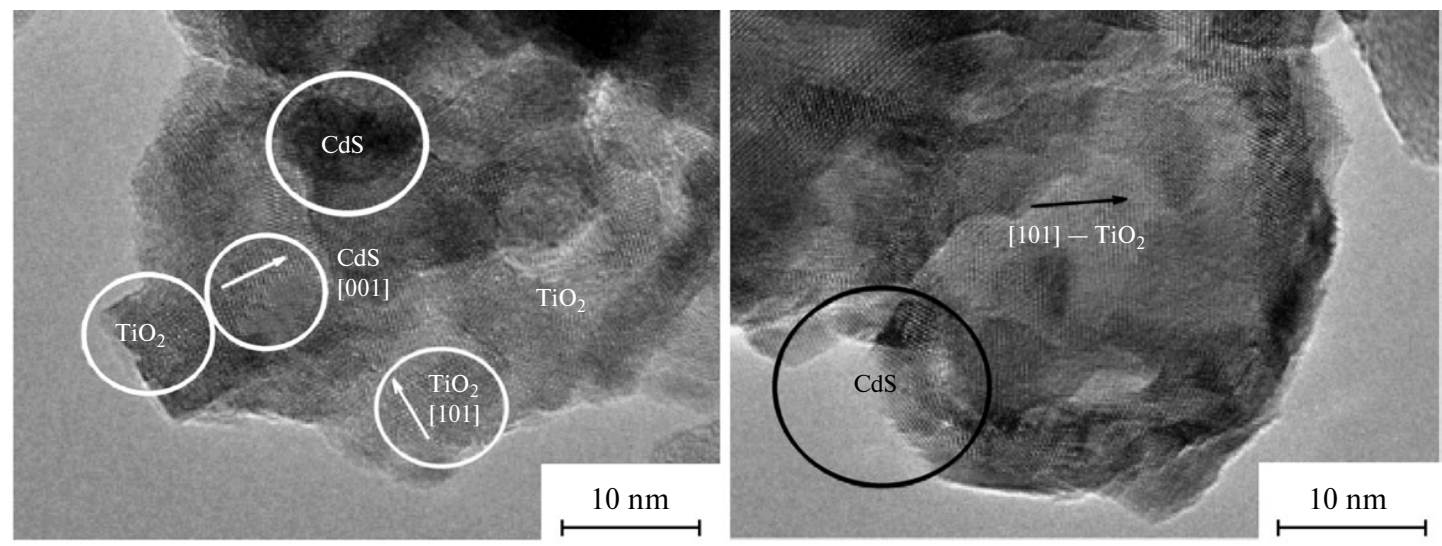

Fig. 5. High-resolution $\mathrm{T} E M$ image of $\mathrm{CdS} @ \mathrm{IiO}_{2}$ powders $\left(\mathrm{IiO}_{2}\right.$ purchased from Degussa $(a)$ and Hombitine $\left.(b)\right)$ obtained from aqueous solutions at $25^{\circ} \mathrm{C}$. Isolated cadmium sulfide nanoparticles tightly adjoin to larger titanium dioxide nanoparticles thus forming a hybrid system.

cadmium, i.e., with the minimum constants of formation of complex ions but sufficient for preventing the formation of oxygen-containing admixtures of cadmium. However, the role of complexing agents in the change in the catalytic activity of the $\mathrm{CdS} @ \mathrm{TiO}_{2}$ system remains unclear so far and requires further studies. It is seen from the data obtained that the deposition of cadmium sulfide on commercial titanium dioxides Hombifine $\mathrm{N}$ and Degussa P25 leads to a high catalytic activity of the hybrid nanoparticles in the case of using complexing agents.

Thus, the design of the hybrid nanoparticles CdS@ $\mathrm{TiO}_{2}$ using complexing agents makes it possible to obtain highly active catalysts of oxidation under the solar light. Further it seems necessary to study reasons for such a high activity of the two-phase photocatalyst $\mathrm{CdS} @ \mathrm{TiO}_{2}$, in particular, to establish the ratio of the electrical potential of heterogeneous nanoparticles of sulfide and dioxide and to study in detail the mechanism of spatial charge separation between the phases. In addition, further works should be aimed at replacing cadmium sulfides with silver and tin sulfides, which are semiconductors with a narrower forbidden band than that of titanium dioxide. In this case, the photocatalyst can correspond to the criteria of green chemistry.

\section{Oxide nanoparticles}

Oxides represent a class of compounds widely used as catalysts, membranes, electrodes of fuel cells, magnetic materials, superconductors, and segnetoelectrics. It should be mentioned that the physical and chemical properties of these compounds can significantly change depending on the granulometric composition and structure..$^{3,62-66}$ However, at present it is insufficient to obtain a material with small particle sizes and high surface, but approaches are needed to the development of specially organized structures, namely, bound systems of nanoparticles with a cer- tain habitus, mutual orientation ratios in the aggregate, and the type of interblock boundaries.

Poor attention was given to the synthesis of nanocrystalline non-stoichiometric transition metal oxides, although these substances in the nanocrystalline state possess practically important properties that substantially extend areas of their application, particularly, in electronics and catalysis. For instance, the single electron transistor based on titanium oxide nanoparticles has recently been constructed first in the world practice. ${ }^{67}$ Such elements of electronic circuits working on quantum tunneling effects are applied to miniaturize electronic processors and memory systems. It is also known that monoxides are used for spraying semiconducting films as an antireflection material in optics. Titanium monoxide is deposited on the silicon dioxide support and is oxidized to titanium dioxide, i.e., titanium monoxide is a source of titanium and oxygen atoms. ${ }^{68}$

Therefore, the methods for formation and stabilization of the formed nanocrystalline structure and the mechanisms of structural transformations in non-stoichiometric transition metal monoxides are of interest. ${ }^{\mathbf{6 6 , 6 9 - 7 1}}$

Chemically pure and single-phase nanoparticles of non-stoichiometric oxides can be obtained by high-energy grinding of polycrystalline powders in a planetary ball mill with a zirconium dioxide lining stabilized with yttrium. 3,72

The procedures of synthesis, thermal treatment, and structural certification of polycrystalline non-stoichiometric transition metal monoxides $\mathrm{MO}_{y}$ used for grinding are published. ${ }^{62-66}$ In these works, polycrystalline powders of non-stoichiometric titanium, vanadium, and niobium monoxides were synthesized by high-temperature $\left(1500-1700^{\circ} \mathrm{C}\right)$ solid-phase sintering of a mixture of metal hydride powders with higher oxides of these metals. The directed synthesis was carried out with allowance for the stoichiometry of the precursors and the required stoichiometry of the monoxides. 
The indicated polycrystalline powders of monoxides with the composition close to stoichiometric $\mathrm{MO}_{1.00}$ were disintegrated in a Retsch PM 200 planetary ball mill. The material of grinding balls and bowls was zirconium dioxide $\mathrm{ZrO}_{2}$ stabilized by yttrium oxide $\mathrm{Y}_{2} \mathrm{O}_{3}$. The ratio of weights of the grinding balls and powder was $10: 1$, and the rotation velocity of the platter of the grinding bowls was $500 \mathrm{rpm}$. Isopropyl alcohol was used as a grinding liquid, which is designed for quenching dry friction between the grinding balls and powder particles and thus prevent abrasion of the balls and grinding of admixtures into the final grinding product, because isopropyl alcohol has a higher self-ignition temperature ( $729 \mathrm{~K}$ ) compared to other frequently used grinding liquids.

The diffraction studies of the milled monoxides were carried out using $\mathrm{Cu}-\mathrm{K} \alpha_{1,2}$ radiation in the step scan mode with $\Delta(2 \theta)=0.03^{\circ}$ in the $2 \theta$ range from 30 to $140^{\circ}$. The instrumental width, i.e., the function of diffractometer resolution, was determined in a special diffraction experiment for a standard powder of lanthanum hexaboride $\mathrm{LaB}_{6}$ (NIST Standard Reference Powder 660a) with the cubic lattice period $a_{\text {cub }}=415.69 \mathrm{pm}$ and a particle size of $\sim 10 \mu \mathrm{m}$.

After high-energy grinding, the diffraction patterns of the monoxides exhibited a significant broadening of all diffraction reflections. The numerical analysis of the diffraction patterns was performed according to an earlier published procedure. ${ }^{73,74}$ The mean particle size was determined taking into account the Scherrer formula ${ }^{75}$ using the Williamson-Hall method, ${ }^{76,77}$ in the framework of which the dimension and deformation contributions to the reflection broadening are divided. The calculation showed that the microdeformation value $\varepsilon$ for nanocrystalline monoxides can reach nearly $0.5 \%$.

The dependence of the mean particle size $D$ of the monoxide powders on the grinding time $t$ is shown in Fig. 6. After grinding, the particle size decreases slowly within $1 \mathrm{~h}$ and tends to some limiting value.

The experimental data are well described by the hyperbolic function $D(t)=D_{0} /(1+b t)+D_{\infty}$, where $D_{0}$ is the initial particle size before grinding, $D_{\infty}$ is the minimum particle size achieved due to grinding, and $b$ is the coefficient related to the softness and fragility of the milled material and shows how rapidly the material can be milled and the minimum particle size can be attained.

To evaluate the particle size, the powders were studied by high-resolution scanning electron microscopy (SEM) on a Zeiss Ultra 55 microscope. The image of the milled powder of vanadium monoxide is presented in Fig. 7 as an example. It is seen that fine scales $20-30 \mathrm{~nm}$ in size adhere to each other and form compact polycrystals (agglomerates), whose sizes vary from 40 to $300 \mathrm{~nm}$, i.e., large particles (agglomerates) consist of numerous fine single-crystal particles $\sim 20-30 \mathrm{~nm}$ in size. The particle sizes of vanadium monoxide determined by two different methods are consistent, which indicates that the data obtained are reliable.

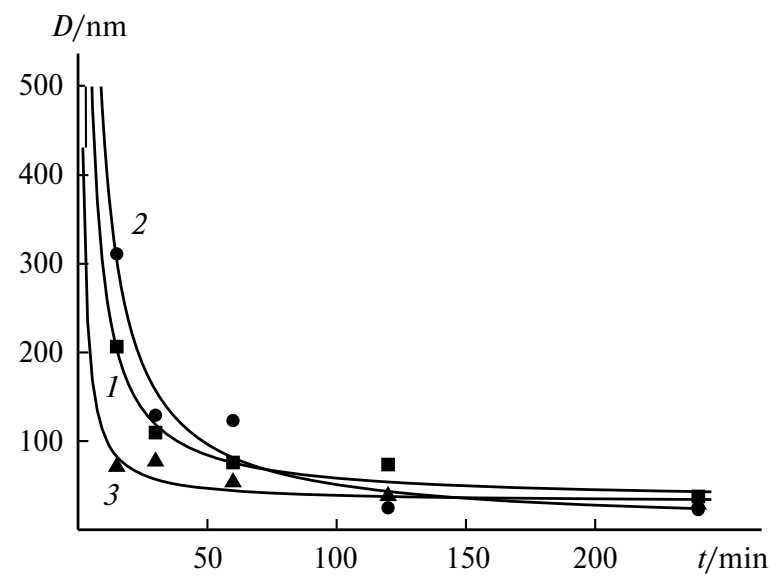

Fig. 6. Mean size of nanoparticles ( $D$ ) of titanium (1), vanadium (2), and niobium (3) monoxides vs duration of grinding in a PM-200 Retsch planetary ball mill with lining and balls of zirconium dioxide stabilized with yttrium at a weght ratio of the balls to powder of $10: 1$ and a rotation velocity of bowls of $500 \mathrm{rpm}$. Each experimental plot is described in terms of a simple hyperbolic dependence.

Thus, monoxide nanoparticles with a size of $20-40 \mathrm{~nm}$ can be obtained by the disintegration of the polycrystalline powders. The achieved nanometric sizes are already sufficient for some applications, but why the minimum sizes lie in the range of several tens of nanometers?

It can be assumed that the minimum value of the grain size or, more exactly, coherent scattering region (CSR) of $\mathrm{X}$-ray radiation for titanium, vanadium, and niobium monoxides in the range from 20 to $40 \mathrm{~nm}$ is related to the intense coalescence of milled particles directly during highenergy grinding.

It is reasonable to assume that both liquid and solid grinding surfactants should be used instead of alcohol to decrease the minimum particle size and to stabilize them at a level of several nanometers, since they will cover freshly split nanoparticles and prevent their approaching to each

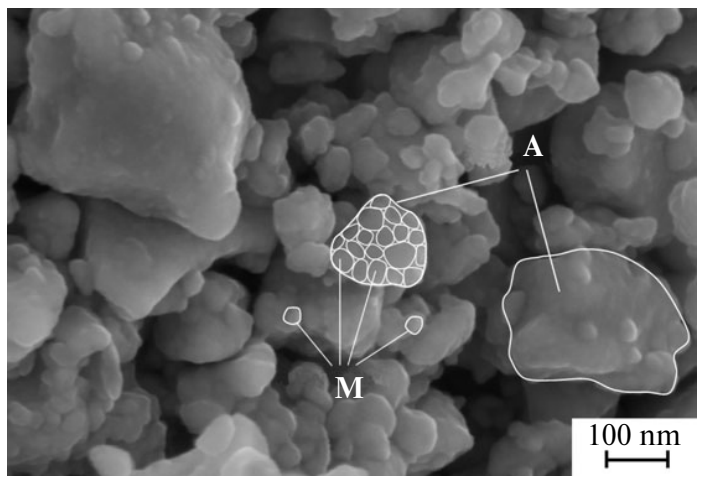

Fig. 7. High-resolution SEM image of vanadium monoxide powders after grinding for $4 \mathrm{~h}$. Agglomerates (A) consisting of many single-crystal particles (M) $20-30 \mathrm{~nm}$ in size are seen. 
other followed by coalescence and coagulation. The first experiments in this direction showed that first of all one should search for molecular substances that cover the whole nanoparticle surface and are also strongly (perhaps, due to covalent bonds) bound to the nanoparticle surface. So, a problem appears to obtain hybrid organic-inorganic nanoparticles surfactant-monoxide.

\section{Carbide - carbide and carbide-metallic nanoparticles}

The hybrid systems based on tungsten carbide $\mathrm{WC}-\mathrm{VC}_{y}$ and $\mathrm{WC}-\mathrm{Co}$ are applied for the production of hard alloys, among which alloys of the $\mathrm{WC}-\mathrm{VC}-\mathrm{Co}$ system are the most propagated. ${ }^{\mathbf{8} 78}$ Hard alloys are widely used in the production of hoggers for the treatment of cast-irons, bronzes, brasses, and ceramics; boring cutting tools and reinforcing elements of jackbits for minerals industry; for the preparation of apparatus details in the production of synthetic diamonds etc.

Taking into account the world tendencies on the use of nanostructured materials, the main stream of the improvement of metal-cutting hard alloys is the formation in them of a nanocrystalline structure of grains of the solid carbide phase with the size $<100 \mathrm{~nm}$. The application of nanocrystalline carbides is considered as the most promising way for the production of nanostructured hard alloys with enhanced hardness, strength, and crack resistance. ${ }^{79}$ The improvement of these characteristics should elongate the service life of a tool under the conditions of impact loads and bend.

Many various methods for the preparation of tungsten carbide WC nanopowders have presently been developed. ${ }^{80,81}$ One of the most propagated and productive chemical methods for the formation of highly dispersed carbide powders is plasmochemical synthesis that makes it possible to obtain nanopowders with the particle size from 10 to $100 \mathrm{~nm}$.

It was attempted ${ }^{\mathbf{8 2 , 8 3}}$ to synthesize hard alloys of the WC-Co system with the superfine-grained structure and to elucidate technological problems that appear when using the traditional method of sintering and affect the phase composition, microstructure, and mechanical properties of the hard alloys obtained from polycrystalline powdered WC-Co mixtures.

In these works, a nanocrystalline powder of tungsten carbide WC with a mean particle size of $35 \mathrm{~nm}$ synthesized by the plasmochemical method, ${ }^{82}$ a microcrystalline cobalt powder, and a nanocrystalline powder of vanadium carbide $\mathrm{VC}_{0.87}$ obtained by high-energy grinding were used as the initial materials for the preparation of the VK6 hard alloy. A powdered mixture VC6-nano containing $93 \mathrm{wt} . \%$ WC, 6 wt. $\% \mathrm{Co}$, and $1 \mathrm{wt} . \% \mathrm{VC}_{0.87}$ was prepared by multistep mixing in a Retsch PM 200 planetary ball mill. Due to this, all components were uniformly distributed over the whole mixture volume. Mixing was carried out in iso- propyl alcohol with a rotation velocity of $300 \mathrm{rpm}$ and a ratio of weights of the balls to the powder of $3: 1$, and the total duration of mixing was $20 \mathrm{~h}$. After mixing, the powders were dried for several hours at $100{ }^{\circ} \mathrm{C}$.

The VK-10 hard alloy was obtained by sintering of the VK10-nano nanocrystalline powdered mixture directly synthesized by the plasmochemical method. ${ }^{82}$ Along with the main components (tungsten carbide WC and cobalt Co), the VK-10-nano powdered mixture contained inhibiting additives of nanocrystalline carbides $\mathrm{VC}, \mathrm{Cr}_{3} \mathrm{C}_{2}$, and $\mathrm{TaC}$ in amounts of $0.3-0.5 \mathrm{wt} . \%$.

To avoid cracking and hogging, the pressed samples were sintered in the two-stage mode: at first slow annealing in a pusher-type industrial furnace under hydrogen atmosphere with a gradual temperature increase to $1150^{\circ} \mathrm{C}$ and then final sintering. The sintering was conducted in a graphite-lined vacuum compression VKPqr 50/50/150 furnace (ALD Vacuum Technologies AG). The mixture was kept for $1 \mathrm{~h}$ at the maximum sintering temperature equal to $1400{ }^{\circ} \mathrm{C}$, and for the first $30 \mathrm{~min}$ the sintering was carried out in a vacuum of $5 \mathrm{mbar}(500 \mathrm{~Pa})$, whereas in the next $30 \mathrm{~min}$ an atmosphere of inert argon under a pressure of $5 \mathrm{MPa}(50 \mathrm{~atm})$ was used. After sintering, the samples of hard alloys got cold as the furnace cooled down.

The microstructure of the nanopowders used for sintering of hard alloys is shown in Fig. 8. The images obtained at a 50000 -fold magnification make it possible to observed individual particles, whose size is $\sim 100 \mathrm{~nm}$. The powders are similar in morphology but differ in origin and composition. For example, the plasmochemical nanopowders WC (see Fig. 8, $a$ ) and VK10-nano (see Fig. 8, $c$ ) have particles with the same shape and close sizes. The powdered mixture VK6-nano (see Fig. 8, $b$ ) was obtained by other method (mixing of the WC nanopowder and the inhibiting additive of vanadium carbide), but no large cobalt particles were detected in it by SEM at different magnifications. This indicates that microcrystalline cobalt was divided and uniformly distributed over the whole volume of the mixture during preparing the VK6-nano mixture due to the intense interaction with solid carbide nanoparticles. The microscopic studies at different magnifications showed that the majority of particles in three nanopowders are joined into large loosen aggregates, whose sizes achieve several micrometers. The aggregation of the nanoparticles is also indicated by the dispersion analysis of the powders performed with a laser analyzer of particle sizes. According to the dispersion analysis results, in all the three nanopowders, the particles are distributed over size in the range from $50 \mathrm{~nm}$ to $9 \mu \mathrm{m}$. Such a wide distribution characterizes the presence of both individual (unbound) nanoparticles and large aggregates with a mean size of 800 , 900 , and $1300 \mathrm{~nm}$ in the powders WC, BK6-nano, and VK10-nano, respectively.

An analysis of the angular dependence of the X-ray diffraction reflection broadening of carbide WC on the 

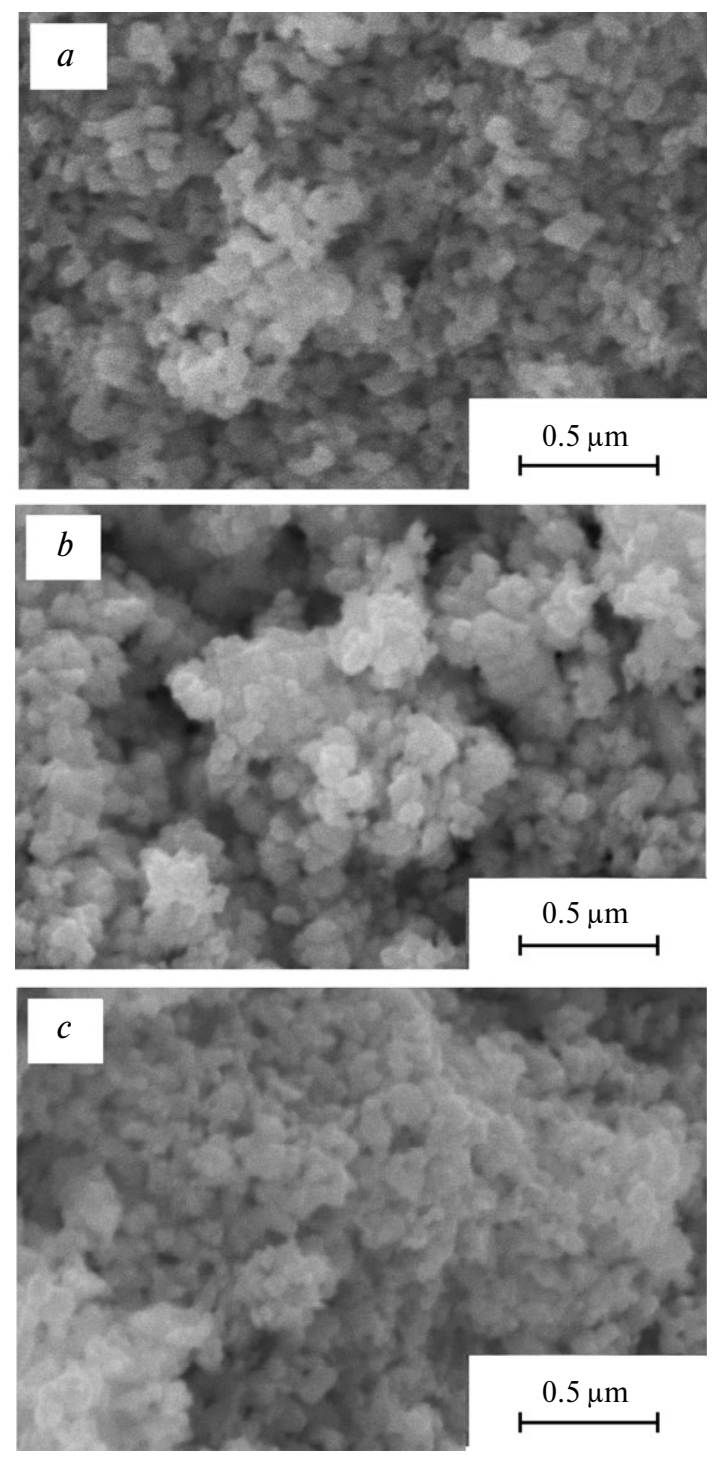

Fig. 8. SEM images of the nanopowders: nanocrystalline powder of tungsten carbide WC $(a)$, powdered mixture VK6-nano $(b)$, and powdered mixture VK10-nano $(c)$.

X-ray patterns detected for various powders gives quite a different result. According to the diffraction data, the mean size of the X-ray CSRs and microstresses in the nanopowders WC, VK6-nano, and VK10-nano are $35 \mathrm{~nm}$ and $0.24 \%, 30 \mathrm{~nm}$ and $0.54 \%$, and $40 \mathrm{~nm}$ and $0.24 \%$, respectively. The X-ray analysis of the WC nanopowder showed that the powder is single-phase and contains only hexagonal tungsten carbide WC (space group $P \overline{6} m 2$ ). The $\mathrm{X}$-ray pattern of the VK10-nano powder mixture contains reflections from hexagonal tungsten carbide and also distinct lines of cobalt. According to the positions of reflections, cobalt is present in this mixture as a high-temperature cubic (space group $F m \overline{3} m$ ) modification. The diffraction pattern detected for the VK6-nano powder mixture exhibits only broadened reflections of hexagonal tung- sten carbide, and no cobalt reflections are observed. This is due to a smaller amount of cobalt in the VK6-nano mixture (compared to that in VK10-nano) and a stronger broadening of its diffraction reflections because of the small size of the particles and their deformations as a result of vigorous abrasion during the preparation of the mixture. In other words, the reflections of nanocrystalline deformed cobalt are so broadened that are merged with the general background of the X-ray diffraction pattern.

The chemical analysis of the initial nanocrystalline powder of tungsten carbide WC, used for obtaining hard alloys, showed that the powder contained $6.14 \mathrm{wt} . \%$ of total carbon and $0.41 \mathrm{wt} . \%$ of free carbon. The hard alloys, whose composition ideally correspond to the quasi-binary cut of the WC-Co phase diagram of the ternary system $\mathrm{W}-\mathrm{Co}-\mathrm{C}$, were obtained due to an excessive content of free carbon. ${ }^{84}$ In fact, it was shown ${ }^{85}$ that special attention should be given to the amount of carbon in the WC nanopowder when sintering hard alloys $\mathrm{WC}-\mathrm{Co}$ from nanocrystalline WC powders. It turned out that the amount of carbon $(5.80-6.12 \mathrm{wt} . \%$ of total carbon and $0.08-0.10 \mathrm{wt} . \%$ of free carbon), which is standard for coarse-grained powders of tungsten carbide $\mathrm{WC}$, is too small for the use of the nanocrystalline powders. The matter is that the nanopowders contain a large amount of oxygen adsorbed on the surface, due to which the partial decarbonization of the nanoparticles occurs during sintering. This shifts the phase composition of the hard alloys to the three-phase region, where the ternary $\eta$-phases $\mathrm{Co}_{3} \mathrm{~W}_{3} \mathrm{C}_{y}$ and $\mathrm{Co}_{6} \mathrm{~W}_{6} \mathrm{C}_{y}$ are formed and induce the embrittlement of the sintered hard alloys. In our case, embrittlement was avoided due to the use of the WC nanopowder with an enhanced carbon content.

It was shown by SEM that the structure of the VK6 and VK10 alloys is rather heterogeneous and contains needle-like inclusions. Samples of the VK6 and VK10 alloys include, along with fine grains $300-400 \mathrm{~nm}$ in size, elongated grains with a length of several micrometers. Nevertheless, the obtained alloys have the minimum porosity A $0.02 \%$ (according to GOST 9391-80). This is caused by the fact that the cavities between large grains are filled with finer grains. This is mostly distinct for the VK6 alloy. In fact, the microstructure of the VK6 alloy is finer and more homogeneous than that of the VK10 alloy. The statistical processing of the data on the grain sizes for several images of the microstructure showed that the mean grain size in the VK6 and VK10 alloys is 0.6 and $0.8 \mu \mathrm{m}$, respectively. The analysis also showed that the grains of the alloys are from $80 \mathrm{~nm}$ to $4 \mu \mathrm{m}$ in size, but more than $70 \%$ of all grains have a size of $200-700 \mathrm{~nm}$.

It follows from the results of measurements of the hardness and microhardness of the sintered hard alloys that they have an enhanced hardness compared to the microcrystalline analogs. ${ }^{86,87}$ The mean values of hardness and microhardness for the samples obtained from the nano- 
crystalline powdered VK6-nano and VK10-nano mixtures are $93.9 \mathrm{HRA}\left(H_{\mathrm{V}}=2100 \mathrm{~kg} \mathrm{~mm}^{-2}\right)$ and $91.4 \mathrm{HRA}$ $\left(H_{\mathrm{V}}=1800 \mathrm{~kg} \mathrm{~mm}^{-2}\right)$, respectively.

It was established by the study performed that the previous technology of pressing and sintering can be remained with the only replacement of microcrystalline WC and Co mixtures with nanopowder mixtures, and this will give alloys with a more compact fine-grained structure and enhanced hardness. For sintering nanostructured hard alloys WC-Co, one should apply WC nanopowders with the increased content of total carbon, which provides the correspondence of the phase composition of the sintered hard alloy to the quasi-binary WC-Co cross section of the phase diagram of the $\mathrm{W}-\mathrm{Co}-\mathrm{C}$ ternary system and excludes the formation of ternary $\eta$-phases that deteriorate the mechanical mixtures of the alloys.

Thus, the use of nanopowders obtained by both grinding and plasmochemical synthesis allows one to obtain hard alloys with improved characteristics. At the same time, the data on tungsten carbide makes it possible to outline further directions of investigation in order to find a way to the synthesis of harder and simultaneously strong alloys: synthesis of powders consisting of hybrid nanoparticles of both $\mathrm{WC}-\mathrm{VC}_{y}$ and $\mathrm{WC}-\mathrm{Co}$. These nanoparticles can be obtained by both chemical deposition methods and high-energy grinding using necessary surfactants as grinding liquids.

The author is grateful to A. I. Gusev, A. A. Valeeva, N. S. Kozhevnikova, A. S. Kurlov, and S. V. Rempel for permanent interest in with work and useful remarks.

This work was financially supported by the Russian Foundation for Basic Research (Project Nos 11-03-00257, 11-08-00314, and 12-08-00016), the Ural Branch of the Russian Academy of Sciences (Project Nos 12-M-23-2001 and 12-C-3-1002), and the Presidium of the Russian Academy of Sciences (Program No. 24 "Basic Foundations of Technologies of Nanostructures and Nanomaterials," Project of the Ural Branch of the Russian Academy of Sciences No. 12-P-234-2003).

\section{References}

1. V. P. Ananikov, I. P. Beletskaya, Dalton Trans., 2011, 40, 4011.

2. H.-E. Schaefer, Nanoscience, Springer Verlag, Berlin, 2010, $772 \mathrm{pp}$.

3. A. A. Rempel, Russ. Chem. Rev., 2007, 76, 435.

4. H. Gleiter, Nanostruct. Mater., 1992, 1, 1.

5. R. W. Siegel, J. Phys. Chem. Solids, 1994, 55, 1097.

6. Yu. I. Petrov, Fizika malykh chastits [Physics of Small Particles], Nauka, Moskva, 1982, 360 pp. (in Russian).

7. L. N. Larikov, Metallofizika [Metallophysics], 1992, 1, 3 (in Russian).

8. L. E. McCandlish, B. H. Kear, B. K. Kim, Nanostruct. Mater., 1992, 1, 119.
9. R. A. Andrievskiy, Russ. Chem. Rev., 1994, 63, 411.

10. A. P. Alivisatos, Science, 1996, 271, 933.

11. A. I. Gusev, Usp. Fiz. Nauk [Success in Physical Sciences], 1998, 168, 55 (in Russian).

12. A. I. Gusev, A. A. Rempel, Nanokristallicheskie Materialy [Nanocrystalline Materials], Fizmatlit, Moscow, 2000, 222 pp. (in Russian).

13. A. L. Buchachenko, Russ. Chem. Rev., 2003, 72, 375.

14. Yu. D. Tret'yakov, Russ. Chem. Rev., 2003, 72, 651.

15. A. I. Gusev, A. A. Rempel, Nanocrystalline Materials, Cambridge Inter. Sci. Publ., Cambridge, 2004.

16. A. A. Rempel, N. S. Kozhevnikova, A. J. G. Leenaers, S. Van den Berghe, J. Cryst. Growth, 2006, 280, 300.

17. A. A. Rempel, N. S. Kozhevnikova, S. Van den Berghe, W. Van Renterghem, Phys. Stat. Sol. (B), 2006, 242, R61.

18. D. V. Labyrina, A. A. Rempel, Abstr. Russian-German Travelling Seminar 2008 "Nanotechnology in German Universities and Scientific Research Centers" (June 18-28, 2008, Frankfurt am Main-Karlsruhe-Stuttgart-Munchen-ErlangenWurzburg, Germany), Erlangen LKS, 2008, 13.

19. A. A. Rempel, A. A. Valeeva, N. S. Kozhevnikova, Pis'ma Zh. Esp. Teor. Fiz., 2010, 92, 167 [JETP Lett. (Engl. Transl.), 2010, 92, No. 3].

20. H.-E. Schaefer, F. Baier, M. A. Müller, K. J. Reichle, K. Reimann, A. A. Rempel, Kiminori Sato, Feng Ye, Xiangyi Zhang, W. Sprengel, Phys. Status Solidi (B), 2011, 248, 2290.

21. A. A. Lemke, A. A. Rempel, Zh. Obshch. Khim., 2012, 82, 1596 [Russ. J. Gen. Chem. (Engl. Transl.), 2012, 82, No. 1].

22. A. A. Rempel, Fiz. Tverd. Tela [Solid State Physics], UGTU-UPI, Yekaterinburg, 2007, 175 pp. (in Russian).

23. S. I. Sadovnikov, N. S. Kozhevnikova, V. G. Pushin, A. A. Rempel, Neorg. Mater., 2012, 48, 26 [Inorg. Mater. (Engl. Transl.), 2012, 48, No. 1].

24. N. S. Kozhevnikova, A. S. Kurlov, A. A. Uritskaya, A. A. Rempel, Zh. Strukt. Khim., 2004, 45, 156 [J. Struct. Chem. (Engl. Transl.), 2012, 45].

25. R. A. Andrievskii, Nanostrukturnye materialy [Nanostructured Materials], Akademiya, Moscow, 2005, 192 pp. (in Russian).

26. A. A. Rempel, N. S. Kozhevnikova, S. V. Rempel, Russ. Chem. Bull. (Int. Ed.), 2013, 62, 398 [Izv. Akad. Nauk, Ser. Khim., 2013, 400].

27. V. A. Oleinikov, A. V. Sukhanova, I. R. Nabiev, Ros. Nanotekh. [Russian Nanotechnologies], 2007, 2, 160 (in Russian).

28. S. V. Rempel, N. S. Kozhevnikova, N. N. Aleksandrova, A. A. Rempel, Neorg. Mater., 2011, 47, 1 [Inorg. Mater. (Engl. Transl.), 2011, 47, No. 1].

29. G. Mountrichas, S. Pispas, N. Tagmatarchis, Invest Ophthalmol. Vis Sci., 2007, 56, 3214.

30. A. M. Smith, H. Haurn, A. M. Indel, S. Nie, Aqq. Sci. Rev., 2008, 22, 452.

31. A. M. Smith, H. Duan, A. M. Mohs, S.Nie, Adv. Drug. Deliv. Rev., 2008, 17, 1226.

32. X. Gao, Y. Cui, R. M. Levenson, L. W. Chung, S. Nie, Nat. Biotechnol., 2004, 22, 959.

33. U. Xianlu, Y. Melin, L. W. Chung, Onkology Sci., 2005, 13, 219.

34. N. S. Kozhevnikova, A. S. Vorokh, A. A. Rempel, Zh. Obshch. Khim., 2010, 80, 250 [Russ. J. Gen. Chem. (Engl. Transl.), 2010, 80, No. 2].

35. N. M. Dyatlova, V. Ya. Temkina, K. I. Popov, Kompleksony i kompleksonaty metallov [Complexones and Metal Complexonates], Khimiya, Moscow, 1988, 544 pp. (in Russian). 
36. S. V. Rempel, A. A. Razvodov, M. S. Nebogatikov, E. V. Shishkina, V. Ya. Shur, A. A. Rempel, Fiz. Tverd. Tela, 2013, 55, 567 [Russ. Phys. Sol. State (Engl. Transl.), 2013, 55, No. 37].

37. A. S. Vorokh, A. A. Rempel, Dokl. Akad. Nauk, 2007, 413, 743 [Dokl. Chem. (Engl. Transl.), 2007].

38. A. S. Vorokh, A. A. Rempel, Pis'ma Zh. Eksp. Teor. Fiz., 2010, 91, 106 [JETP Lett. (Engl. Transl.), 2010, 91, No. 2].

39. A. Rempel, A. Magerl, Acta Crystallogr. A, 2010, 66, 479.

40. A. A. Rempel, A. S. Vorokh, R. Neder, A. Magerl, Poverkhnost' $^{\prime}$ [Surface], 2011, No. 11, 8 (in Russian).

41. S. S. Voyutskii, Kurs Kolloidnoi Khimii [The Course of Colloidal Chemistry], Khimiya, Moscow, 1975, 512 pp. (in Russian).

42. I. S. Osad'ko, Usp. Fiz. Nauk [Success in Physical Sciences], 2006, 176, 23 (in Russian).

43. A. A. Klochikhin, S. A. Permogorov, A. N. Reznitskii, Fiz. Tverd. Tela, 1997, 39, 1170 [Russ. Phys. Sol. State (Engl. Transl.), 1997, 39, No. 7].

44. N. G. Piven, L. P. Shcherbak, P. I. Feichuk, S. M. Kalitchuk, S. G. Krylyuk, D. V. Korbutyak, Kondensirovannye Sredy i Mezhfaznye Granitsy [Condensed Media and Interface Boundaries], 2006, 8, 315 (in Russian).

45. S. V. Rempel, N. S. Kozhevnikova, N. N. Aleksandrova, A. A. Rempel, Neorg. Mater., 2011, 47, 271 [Inorg. Mater. (Engl. Transl.), 2012, 47, No. 3].

46. S. V. Rempel, N. S. Kozhevnikova, N. N. Aleksandrova, A. A. Rempel, Dokl. Akad. Nauk, 2011, 440, 56 [Dokl. Chem. (Engl. Transl.), 2011].

47. S. V. Rempel, N. N. Aleksandrova, A. A. Rempel, Dal'nevostoch. Zh. Infekts. Patol. [Far Eastern J. Infection Pathologies], 2012, 20, 106 (in Russian).

48. N. S. Kozhevnikova, E. A. Kozlova, A. A. Valeeva, A. A. Lemke, A. S. Vorokh, S. V. Cherepanova, T. P. Lyubina, E. V. Gerasimov, S. V. Tsybulya, A. A. Rempel, Dokl. Akad. Nauk, 2011, 440, 635 [Dokl. Chem. (Engl. Transl.), 2011].

49. N. S. Kozhevnikova, T. I. Gorbunova, A. S. Vorokh, D. N. Bazhin, A. Ya. Zapevalov, V. I. Saloutin, A. A. Rempel, O. N. Chupakhin, Dokl. Akad. Nauk, 2012, 443, 321 [Dokl. Chem. (Engl. Transl.), 2012].

50. E. A. Kozlova, N. S. Kozhevnikova, S. V. Cherepanova, T. P. Lyubina, E. Yu. Gerasimov, V. V. Kaichev, A. V. Vorontsov, S. V. Tsybulya, A. A. Rempel, V. N. Parmon, J. Photochem. Photobiol. A: Chem., 2012, 250, 103.

51. Sh. Higashimoto, N. Kitao, N. Yoshida, T. Sakura, M. Azuma, H. Ohue, Y. Sakata, J. Catal., 2009, 266, 279; V. Keller, P. Bernhardt, F. Garin, J. Catal., 2003, 215, 129.

52. V. Keller, P. Bernhardt, F. Garin, J. Catal., 2003, 215, 129.

53. C. Salazara, M. A. Nanny, J. Catal., 2010, 269, 404.

54. Y. Bessekhouad, D. Robert, J. V. Weber, J. Photochem. Photobiol. A, 2004, 163, 569.

55. L. Wu, J. C. Yu, X. Fu, J. Mol. Catal. A, 2006, 244, 25.

56. L. Spanhel, M. Haase, H. Weller, A. Henglein, J. Am. Chem. Soc., 1987, 109, 5649.

57. R. Vogel, P. Hoyer, H. Weller, J. Phys. Chem., 1994, 98, 3183.

58. A. Kumar, A. K. Jain, J. Mol. Catal. A: Chem., 2001, 165, 265.

59. N. S. Kozhevnikova, A. S. Kurlov, A. A. Uritskaya, A. A. Rempel, Zh. Strukt. Khim., 2004, 45, Appendix, 156 [J. Struct. Chem. (Engl. Transl.), 2004, 45].

60. G. A. Kitaev, A. A. Uritskaya, S. G. Mokrushin, Zh. Fiz. Khim., 1965, 39, 2065 [Russ. J. Phys. Chem. (Engl. Transl.), 1965, 39, No. 8].

61. N. S. Kozhevnikova, A. A. Rempel, F. Hergert, A. Magerl, Thin Solid Films, 2009, 517, 2586.
62. A. A. Valeeva, A. A. Rempel, W. Sprengel, H.-E. Schaefer, Phys. Chem. Chem. Phys., 2003, 5, 2304.

63. A. A. Valeeva, A. A. Rempel, W. Sprengel, H.-E. Schaefer, Phys. Rev. B, 2007, 75, 094107.

64. A. A. Valeeva, A. A. Rempel, M. A. Müller, K. J. Reichle, G. Tang, W. Sprengel, H.-E. Schaefer, Phys. Status Solidi (B), 2001, 224, R1.

65. A. A. Rempel, A. A. Valeeva, Mendeleev Commun., 2010, 20, 101

66. A. A. Valeeva, A. A. Rempel, Perspektiv. Mater. [Advanced Materials], 2011, Special Issue, No. 12, 71 (in Russian).

67. V. Schöllmann, J. Johansson, K. Andersen, D. B. Haviland, J. Appl. Phys., 2000, 88, 6549.

68. X. Chen, S. S. Mao, Chem. Rev., 2000, 107, 2891.

69. M. G. Kostenko, A. A. Valeeva, A. A. Rempel, Zh. Eksp. Teor. Fiz., 2010, 138, 892 [J. Exp. Theor. Phys. (Engl. Transl.), 2010, 138, No. 5].

70. M. G. Kostenko, A. A. Valeeva, A. A. Rempel, Mendeleev Commun., 2012, 22, 245.

71. M. G. Kostenko, A. V. Lukoyanov, V. P. Zhukov, A. A. Rempel, Pis'ma Zh. Eksp. Teor. Fiz., 2012, 96, 557 [JETP Lett. (Engl. Transl.), 2011, 96, No. 8].

72. A. A. Valeeva, Kh. Shretner, A. A. Rempel, Neorg. Mater., 2011, 41, 464 [Inorg. Mater. (Engl. Transl.), 2011, 41, No. 4].

73. H. M. Rietveld, J. Appl. Crystallogr., 1969, 2, 65.

74. A. A. Rempel, A. I. Gusev, Fiz. Tverd. Tela, 2000, 42, 1243 [Russ. Phys. Sol. State (Engl. Transl.), 2000, 92, No. 7].

75. B. E. Warren, $X$-Ray Diffraction, Dower Publications, New York, 1990, $381 \mathrm{pp}$.

76. W. H. Hall, Proc. Phys. Soc. London, Sect. A, 1949, 62, 741.

77. W. H. Hall, G. K. Williamson, Proc. Phys. Soc. London, Sect. $B, 1951,64,937$.

78. A. A. Rempel, R. Würschum, H.-E. Schaefer, Phys. Rev. B, 2000, 61, 5945.

79. L. I. Klyachko, V. A. Fal'kovskii, A. M. Khokhlov, Tverdye splavy na osnove karbida vol'frama s tonkodispersnoi strukturoi [Hard Alloys Based on Tungsten Carbide with Finely Dispersed Structure], Ruda i Metally, Moscow, 1999, 48 pp. (in Russian).

80. A. I. Gusev, Nanomaterialy, nanostruktury, nanotekhnologii [Nanomaterials, Nanostructures, and Nanotechnologies], Fizmatlit, Moscow, 2005, 416 pp. (in Russian).

81. Z. Zak Fang, Xu Wang, Taegong Ryu, Kyu SupHwang, H. Y. Sohn, Intern. J. Refr. Met. Hard Mater, 2009, 27, 288.

82. A. S. Kurlov, A. A. Rempel, Yu. V. Blagoveshchenskii, A. V. Samokhin, Yu. V. Tsvetkov, Dokl. Akad. Nauk, 2011, 439, 215 [Dokl. Chem. (Engl. Transl.), 2011].

83. A. S. Kurlov, A. Leenaers, S. van den Berghe, M. Scibetta, H. Schröttner, A. A. Rempel, Adv. Mater. Sci., 2011, 27, 165.

84. A. F. Guillermet, Metallurg. Transact. AIME A, 1989, 20A, 935.

85. A. S. Kurlov, A. A. Rempel, Neorg. Mater., 2009, 45, 429 [Inorg. Mater. (Engl. Transl.), 2009, 49, No. 4].

86. Poroshkovaya metallurgiya $i$ napylennye pokrytiya [Powder Metallurgy and Coating Spraying], Ed. B. S. Mitin, Metallurgiya, Moscow, 1987, 184 pp. (in Russian).

87. W. Schedler, Hartmetall für den Praktiker: Aufbau, Herstellung, Eigenschaften und industrielle Anwendung einer modernen Werkstoffgruppe, VDI-Verlag, Düsseldorf, 1988, 558 pp.

Received December 27, 2012; in revised form March 4, 2013 